\title{
Effect of staining solutions on color of pre-reacted glass-ionomer containing composites
}

\author{
Fucong $\operatorname{TIAN}^{1}$, Adrian $U$ Jin $\mathrm{YAP}^{2,3,4}$, Xiaoyan WANG ${ }^{1}$ and Xuejun $\mathrm{GAO}^{1}$ \\ ${ }^{1}$ Department of Cariology and Endodontology, School and Hospital of Stomatology, Peking University, 22 Zhonggwancun South Street, Hai Dian \\ District Beijing, 100081, China \\ ${ }^{2}$ Raffles Hospital, 585 North Bridge Road, 188770, Singapore \\ ${ }^{3}$ Department of Restorative Dentistry, Faculty of Dentistry, National University of Singapore, Singapore \\ ${ }^{4}$ School of Science and Technology, SIM University, 461 Clementi Road, 599491, Singapore \\ Corresponding author, Xiaoyan WANG; E-mail: wangxiaoyan@pkuss.bjmu.edu.cn
}

\begin{abstract}
This study investigated the color stability of pre-reacted glass-ionomer containing composite restoratives. The materials evaluated included one regular (Beautifil II [BF]), two flowable (Beautifil Flow [F02, F10]) and two recently introduced flowable "plus" (Beautifil Flow Plus [F00, F03]) pre-reacted glass-ionomer containing composite restoratives. Twelve specimens of each material (A3 shade) were fabricated, allowed to set for $24 \mathrm{~h}$ at $37^{\circ} \mathrm{C}$ and randomly divided into 4 groups. After baseline spectrophotometric (Crystaleye, Olympus) color measurements, specimens were immersed in water, cola, red wine and coffee for 7 days. Post-immersion color measurements were taken and color changes $(\Delta E)$ were computed accordingly. Statistical analysis was done using ANOVA and post-hoc Scheffe's test $(p<0.05)$. For pre-reacted glass-ionomer containing composites, color changes after immersion in coffee and red wine were significantly greater than in cola and water. Differences in $\Delta E$ values between materials were solution dependent. The least color change was generally observed with the flowable "plus" pre-reacted glass-ionomer containing composites.
\end{abstract}

Keywords: Pre-reacted glass-ionomer containing composite, Color stability, Flowable resin

\section{INTRODUCTION}

Hybrid restorative materials, like resin-modified glass ionomer cements (RMGICs) and compomers, were developed to combine the fluoride releasing properties of glass ionomer cements and aesthetics of composite resins. Resin is incorporated into RMGICs by substituting acidic co-polymers with a water-HEMA (Hydroxyethyl methacrylate) mixture or the use of acidic co-polymers with methacrylate side-chains. As resin constitutes only 4.5 to $6 \%$ of the set material, RMGICs retain a significant acid-base reaction as part of their overall curing process and possess many characteristics of conventional glass ionomer cements including chemical bonding to teeth and fluoride release/re-charge ${ }^{1)}$. Compomers or polyacidmodified composites also contain the essential components of glass ionomer cements (i.e. fluoroaluminosilicate glass and polyacrylic acid). The acid component is, however, dehydrated and incorporated in the resin matrix. Acid-base reaction occurs gradually after light polymerization when the dehydrated acid is activated through water sorption. Water sorption needed for the acid-base reaction to take place has been shown to compromise the aesthetics and physical properties of compomers ${ }^{2)}$.

Pre-reacted glass ionomer filled composites (Giomer) are the latest category of hybrid tooth colored restorative materials. They are based on "PRG" technology in which pre-reacted glass ionomer cements are used as fillers. Fluoride release/re-charge of giomers are significantly better than compomers but lower than glass ionomer cements $^{3,4}$. A recent study has reported reduced dental plaque formation and bacterial adherence on giomers when compared to composites ${ }^{5}$. Long-term clinical studies on first generation giomer restoratives has been very promising. Matis et al. found no significant difference between giomer and micro-filled composite restorations in all the parameters evaluated after 3 years ${ }^{6}$. Gordan et al. evaluated the clinical performance of giomer restorations over eight years and reported no restoration failure ${ }^{7}$. Significant changes were, however, observed for marginal adaptation and staining.

To ensure good aesthetics, restorative materials must be resistant to discoloration by staining food and beverages. The color stability and staining susceptibility of composites, compomers and glass ionomers have been widely investigated ${ }^{8-10)}$. Results suggest that most materials are susceptible to staining by "dark" beverages while distilled water causes no perceptible color change. The staining potential of giomers has not been well investigated. Flowable "plus" giomer restoratives that combine flowable delivery with strength, durability and aesthetics of "hybrid" composites were recently introduced. This study investigated the effect of staining solutions on the color of giomer restoratives. It was postulated that color changes are both material and staining solution dependent.

\section{MATERIALS AND METHODS}

Five pre-reacted glass-ionomer containing composite (Giomer) restoratives of different viscosities were selected for this study. They included one regular (Beautifil II [BF]), two flowable (Beautifil Flow [F02, 
Table 1 Chemical composition of the different giomer restoratives

\begin{tabular}{|c|c|c|c|}
\hline Materials & Batch number & Composition & $\mathrm{w} \%$ \\
\hline Beautifil II & 020852 & $\begin{array}{l}\text { Bis-GMA (Bisphenylglycidyl Dimethacrylate) } \\
\text { TEGDMA (Triethylenglycol Dimethacrylate) } \\
\text { Aluminofluoro-borosilicate glass } \\
\mathrm{Al}_{2} \mathrm{O}_{3} \text {, DL-Camphorquinone }\end{array}$ & $\begin{array}{c}7.5 \\
5 \\
70\end{array}$ \\
\hline Beautifil Flow & $\begin{array}{l}\text { F02: } 120730 \\
\text { F10: } 120715\end{array}$ & $\begin{array}{l}\text { Bis-GMA } \\
\text { TEGDMA } \\
\text { Aluminofluoro-borosilicate glass } \\
\mathrm{Al}_{2} \mathrm{O}_{3} \text {, DL-Camphorquinone }\end{array}$ & $\begin{array}{l}20-30 \\
5-8 \\
40-50\end{array}$ \\
\hline Beautifil Flow Plus & $\begin{array}{l}\text { F00: } 071012 \\
\text { F03: } 021005\end{array}$ & $\begin{array}{l}\text { Bis-GMA } \\
\text { TEGDMA } \\
\text { Aluminofluoro-borosilicate glass } \\
\mathrm{Al}_{2} \mathrm{O}_{3} \text {, DL-Camphorquinone }\end{array}$ & $\begin{array}{l}15-25 \\
12-14 \\
50-60\end{array}$ \\
\hline
\end{tabular}

F10]) and two recently introduced flowable "plus" (Beautifil Flow Plus [F00, F03]) giomers. The compositions of the materials are listed in Table 1. Twelve specimens (10 $\mathrm{mm}$ diameter, $1.0 \mathrm{~mm}$ thick) of each material (A3 shade) were fabricated using a customized cylindrical mold. The top and bottom surfaces were covered with mylar strips and excess material was extruded by pressure application with a glass slide. Light polymerization was carried out using a highintensity $\left(1,100 \mathrm{~mW} / \mathrm{cm}^{2}\right) \mathrm{LED}$ curing light (Bluephase, Ivoclar Vivadent, Schaan, Liechtenstein) for $20 \mathrm{~s}$. The mylar strips were removed and the specimens were allowed to set for $24 \mathrm{~h}$ at $37^{\circ} \mathrm{C}$ and $95 \%$ relative humidity.

The specimens were then randomly divided into 4 groups and immersed into the following solutions: distilled water (control medium), cola drink, red wine and coffee. The $\mathrm{pH}$ of the solutions was measured with a $\mathrm{pH}$ meter (Seveneasy, Mettler Toledo $\mathrm{GmbH}$, Schwerzenbach, Switzerland) prior to immersion of the specimens. With the exception of cola, immersion was carried out in 12 -well plates of $5 \mathrm{~mL}$ at $37^{\circ} \mathrm{C}$. For immersion in cola drink, the specimens were placed into a $600 \mathrm{~mL}$ bottle and the cover was fastened to avoid gas leakage. All solutions were changed daily for 7 days.

Color parameters were measured with a spectrophotometer (Crystaleye, Olympus, Tokyo, Japan) before and after immersion on a white background. Measurements were repeated three times in the center of the specimen. CIE $L^{*} a^{*} b^{*}$ values were recorded and color changes $(\Delta E)$ were computed according to formula $\left(\Delta E^{*}=\left[\left(\Delta L^{*}\right)^{2}+\left(\Delta a^{*}\right)^{2}+\left(\Delta b^{*}\right)^{2}\right]^{1 / 2}\right)$ for each specimen. Statistical analysis was performed using ANOVA and post-hoc Scheffe's test at the significance level of 0.05 .

\section{RESULTS}

The $\mathrm{pH}$ values of distilled water, cola, red wine and coffee were $7.17 \pm 0.02,2.38 \pm 0.12,3.42 \pm 0.01$ and $6.28 \pm 0.06$ respectively. Mean $\Delta E, \Delta L^{*}, \Delta a^{*}, \Delta b^{*}$ values and results of statistical analysis are shown in Tables 2 and 3 respectively. Delta $E$ values ranged from 0.60 to 15.57 for the various materials and solutions. The lowest color change was generally observed after immersion in water while the highest was noted with exposure to coffee. For all materials evaluated, color changes after immersion in coffee and red wine were significantly greater than in cola and water. No significant difference in $\Delta E$ values was observed between immersion in cola and water.

Differences in $\Delta E$ values between materials were immersion solution dependent. For the control group (water), the color change observed with F02 was significantly greater than F03, F00 and BF. For all staining solutions, $\Delta E$ values of $\mathrm{BF}$ were the highest. After immersion in cola and coffee, the color change of BF was significantly greater than F00 and F03 respectively. The color change observed with $\mathrm{BF}$ after exposure to red wine was significantly greater than all the other materials. F02 was also significantly less color stable than F10, F03 and F00 in red wine.

\section{DISCUSSION}

The present study investigated the color changes associated with the range of currently available giomer restoratives after immersion in distilled water, cola, red wine and coffee. The spectrum of giomer restoratives generally contained the same resins and fillers but in different quantities (Table 1). While the resins are similar to those employed with other dental composites (i.e. Bis-GMA and TEGDMA), the fillers are predominantly aluminofluoro-borosilicate glass, a major component of glass ionomer cements. Depending on product, these glasses constitute 40 to $70 \%$ of the restorative material. A small amount of aluminum oxide fillers are also utilized. To standardize and achieve the smoothest surface finish possible, maylar strips were employed. The latter also curtails the influence of variations in finishing/polishing techniques and procedures on color changes which has been planned for future work. Water was used as the control medium as it has been shown to cause no perceptible color change in glass ionomer and composite restorative materials ${ }^{8)}$. Under clinical settings, the human eye can only sense $\Delta E$ values of 3.3 or greater ${ }^{11)}$. As none of the giomer 
Table 2 Mean $\Delta E, \Delta L^{*}, \Delta a^{*}, \Delta b^{*}$ values (standard deviation in parenthesis) of the various giomer materials after immersion in the different solutions

\begin{tabular}{|c|c|c|c|c|c|c|}
\hline Solution & & $\mathrm{BF}$ & F00 & F02 & F03 & F10 \\
\hline \multirow{4}{*}{ Water } & $\Delta E$ & $0.60(0.26)$ & $0.65(0.26)$ & $2.34(0.44)$ & $0.68(0.13)$ & $1.72(0.87)$ \\
\hline & $\Delta L^{*}$ & $-0.33(0.14)$ & $0.08(0.24)$ & $-0.37(0.13)$ & $0.41(0.34)$ & $0.11(0.36)$ \\
\hline & $\Delta a^{*}$ & $-0.25(0.08)$ & $-0.16(0.12)$ & $0.04(0.07)$ & $0.03(0.16)$ & $-0.06(0.14)$ \\
\hline & $\Delta b^{*}$ & $0.25(0.48)$ & $-0.58(0.23)$ & $2.31(0.06)$ & $-0.41(0.24)$ & $1.23(1.67)$ \\
\hline \multirow{4}{*}{ Cola } & $\Delta E$ & $3.86(1.55)$ & $0.34(0.09)$ & $1.98(0.10)$ & $1.36(1.24)$ & $1.63(0.28)$ \\
\hline & $\Delta L^{*}$ & $0.20(0.53)$ & $0.16(0.10)$ & $-0.45(0.27)$ & $-0.58(1.67)$ & $-0.10(0.11)$ \\
\hline & $\Delta a^{*}$ & $-0.24(0.12)$ & $-0.23(0.11)$ & $0.08(0.15)$ & $-0.08(0.13)$ & $-0.01(0.11)$ \\
\hline & $\Delta b^{*}$ & $3.82(1.57)$ & $-0.11(0.15)$ & $1.91(0.10)$ & $-0.55(0.70)$ & $1.63(0.29)$ \\
\hline \multirow{4}{*}{ Red wine } & $\Delta E$ & $13.22(1.20)$ & $6.67(0.23)$ & $9.91(0.21)$ & $6.78(0.29)$ & $7.61(0.68)$ \\
\hline & $\Delta L^{*}$ & $11.95(1.05)$ & $6.35(0.24)$ & $9.81(0.21)$ & $6.42(0.26)$ & $7.33(0.50)$ \\
\hline & $\Delta a^{*}$ & $-2.40(0.74)$ & $-1.63(0.34)$ & $-1.21(0.28)$ & $-1.52(0.15)$ & $-1.53(0.86)$ \\
\hline & $\Delta b^{*}$ & $5.09(0.75)$ & $1.18(0.19)$ & $-0.12(0.81)$ & $1.57(0.23)$ & $-0.29(1.48)$ \\
\hline \multirow{4}{*}{ Coffee } & $\Delta E$ & $15.57(2.35)$ & $7.86(3.54)$ & $11.89(0.98)$ & $5.50(3.42)$ & $12.18(2.26)$ \\
\hline & $\Delta L^{*}$ & $15.08(1.75)$ & $6.59(2.93)$ & $11.21(1.60)$ & $5.05(3.39)$ & $11.06(1.63)$ \\
\hline & $\Delta a^{*}$ & $-0.34(1.16)$ & $-1.29(1.72)$ & $2.85(2.19)$ & $-0.14(0.90)$ & $-0.86(0.82)$ \\
\hline & $\Delta b^{*}$ & $-3.4(2.45)$ & $-3.92(1.78)$ & $1.63(0.96)$ & $-2.00(0.69)$ & $-4.91(1.84)$ \\
\hline
\end{tabular}

Table 3 Results of statistical analysis

\begin{tabular}{lc}
\hline & Comparison between solutions \\
\hline BF & Coffee, red wine $>$ cola, water \\
F00 & Coffee, red wine $>$ water, cola \\
F02 & Coffee $>$ red wine $>$ water, cola \\
F03 & Red wine, coffee $>$ cola, water \\
F10 & Coffee $>$ red wine $>$ water, cola \\
\hline & Comparison between materials \\
\hline Water & F02 $>$ F03, F00, BF \\
Cola & BF $>$ F00 \\
Red wine & BF $>$ F02 $>$ F10, F03, F00 \\
Coffee & BF $>$ F03 \\
\hline
\end{tabular}

$>$ indicates statistically significant differences in $\Delta E$ values (results of one-way ANOVA and Scheffe's post-hoc test).

restoratives had $\Delta E$ values greater than 3.3 after immersion in distilled water, color change is not clinically distinguishable. The greatest color change in water was observed for F02 and $\Delta E$ values were significantly higher than the regular and the flowable "plus" giomers.

Ardu et al. studied the long-term color of 12 composite materials when continuously exposed to staining agents ${ }^{10)}$. They found that wine had the highest staining potential followed by coffee, tea, orange juice and cola. For giomers, coffee generally caused the most staining. Immersion in coffee and red wine resulted in significantly greater color changes than exposure to cola and water. For all giomer restoratives, color changes with coffee and red wine were clinically perceivable as $\Delta E$ values were greater than 3.3 and ranged from 5.50 to 15.57. Detailed analysis of the three color attributes revealed that color change after exposure to coffee and red wine was mainly caused by changes in the $L^{*}$ or lightness variable that is proportional to "value" in the Munsell system. The $a^{*}$ and $b^{*}$ variables are chromacity coordinates designating red/green and yellow/blue axes respectively. No significant difference in $\Delta E$ values was observed between cola and water. The generally undetectable color changes were predominantly influenced by alterations in the $b^{*}$ variable (Table 2). While the previous generation of giomers (BF, F02 and F10) became more yellow (+ $b$ values), color of the new flowable "plus" materials (F00 and F03) shifted towards the blue range on $b^{*}$ axes (i.e. $-b$ values).

The effect of $\mathrm{pH}$ on the surface texture of commonly used glass ionomer based/containing restorative materials including giomers was investigated by Mohamed-Tahir and Yap ${ }^{12}$. With the exception of the composite control, surface roughness of all glass ionomer based/containing materials evaluated was significantly affected by low $\mathrm{pH}$. BF specimens conditioned in citric acid of $\mathrm{pH} 2$ and 3 were significantly rougher than those conditioned in $\mathrm{pH} 4$ to 7 . Citric acid was chosen as the erosive medium as it is the most common acid found in fruit juices/drinks and is frequently added to foodstuff. It was suggested that under acidic conditions, $\mathrm{H}^{+}$ions diffused into the glass ionomer components and replaced metal cations in the matrix. The free cations diffuse outwards and are released from the surface. As the metal cations in the matrix decreases, more would be extracted from the surrounding glass particles, causing them to 
dissolve ${ }^{13)}$. With time, the material presents a roughened surface with voids and protruded, undissolved glass particle resulting in greater water and food colorant absorption $^{14)}$.

The current results, however, suggest that the color changes after immersion in the various staining solutions cannot be attributed to $\mathrm{pH}$-related surface changes alone. Cola which had the lowest ( $\mathrm{pH}$ 2.38) didn't cause significant color changes while coffee which was only mildly acidic ( $\mathrm{pH}$ 6.28) produced the greatest discoloration. Discoloration of restorative materials is multi-factorial in nature and factors including titratable acidity, degree of resin polymerization as well as food colorant absorption/penetration may also contribute to the amount of staining observed. While $\mathrm{pH}$ indicates the strength of acidity, titratable acidity reflects the total amount of acid present (i.e. total acidity) and is determined by titration against a standard solution of sodium hydroxide. There is no direct relation between $\mathrm{pH}$ and total acidity. The three primary acids found in wine are tartaric, malic and citric acid. It may also contain smaller amounts of acetic, butyric, lactic and succinic acids. Coffee contains some 22 types of acids with citric acid, acetic acid and high molecular weight acids contributing to most of its total acidity ${ }^{15)}$. Other acids include chlorogenic, formic, quinic, malic and phosphoric acids. The relative total acidity of the staining solutions and its effect on the matrix and fillers of giomers warrants further investigation. It is possible for a solution with a high $\mathrm{pH}$ to have high total acidity.

Dental composite color stability has also been associated with the degree of resin conversion ${ }^{16)}$. A correlation was also found between degree of conversion and composite solubility as well as solubility and salivary sorption ${ }^{17)}$. Incompletely polymerized composites have greater susceptibility to discoloration due to the larger amount of residual mononers available to form colored degraded products ${ }^{18)}$. The degree of conversion is influenced by Bis-GMA content and co-monomer types with TEGDMA mixtures resulting in higher conversion than BisEMA (Ethoxylated Bisphenol-A Dimethacrylate) blends ${ }^{19)}$. For Bis-GMA/TEGDMA formulations, the resin matrix has a greater influence on polymerization stress, reaction rate and degree of conversion, whereas filler fraction showed a stronger influence on shrinkage and modulus ${ }^{20)}$. The resin matrix of the giomer restoratives were all based on Bis-GMA/TEGDMA mixtures. Bis-GMA molecules are highly viscous and require the addition of low molecular weight monomers to achieve a workable consistency upon filler incorporation. TEGDMA is often employed as the diluent monomer for Bis-GMA due to its low viscosity and excellent copolymerization characteristics. Although the incorporation of more TEGDMA increases degree of conversion, mechanical properties may be compromised ${ }^{21)}$. The lower staining susceptibility of the flowable "plus" giomers may be attributed in part to the relatively higher TEGDMA content when compared to their conventional counterparts. Amongst the materials evaluated, the regular giomer $\mathrm{BF}$ had the highest filler loading (70 weight percent). Any dissolution of the resin matrix would lead to greater exposure of the irregularly arranged filler particles resulting in rougher surfaces. The roughened surfaces are easily stained by mechanical absorption ${ }^{14)}$. Absorption and penetration of colorants is further enhanced by the compatibility of the resin matrix (i.e. polymer phase) with yellow colorants of coffee ${ }^{22)}$. The latter also helps explain the higher $\Delta E$ values observed with coffee and corroborates the findings of other studies on dental composites ${ }^{23,24)}$.

\section{CONCLUSION}

Within the limitations of this study, the following conclusions can be made:

- Coffee and red wine causes significantly more color change of giomers than water and cola.

- The color changes associated with coffee and red wine are clinically perceivable as $\Delta E$ values are greater than 3.3.

- Differences in color change between materials are solution dependent.

- For all staining solutions, the least color change was generally observed with the flowable "plus" giomers.

\section{ACKNOWLEDGMENTS}

The authors would like to thank Shofu Corporation for providing the materials for this research.

\section{REFERENCES}

1) Burke FM, Ray NJ, McConnell RJ. Fluoride containing restorative materials. Int Dent J 2006; 56: 33-43.

2) Musanje L, Shu M, Darvell BW. Water sorption and mechanical behavior of cosmetic direct restorative materials in artificial saliva. Dent Mater 2001; 17: 394-401.

3) Yap AU, Tham SY, Zhu LY, Lee HK. Short-term fluoride release from various aesthetic restorative materials. Oper Dent 2002; 27: 259-265.

4) Itota T, Carrick TE, Yoshiyama M, McCabe JF. Fluoride release and re-charge in Giomer, Compomer and Resin Composite. Dent Mater 2004; 20: 789-795.

5) Saku S, Kotake H, Scougall-Vilchis RJ, Ohashi S, Hotta M, Horiuchi S, Hamada K, Asaoka K, Tanaka E, Yamamoto K. Antibacterial activity of composite resin with glass-ionomer filler particles. Dent Mater J 2010; 29: 193-198.

6) Matis BA, Cochran MJ, Carlson TJ, Guba C, Eckert GJ. A three-year clinical evaluation of two dentin bonding agents. $J$ Am Dent Assoc 2004; 135: 451-457.

7) Gordan VV, Mondragon E, Watson RE, Garvan C, Mjör IA. A clinical evaluation of a self-etching primer and a giomer restorative material: results at eight years. J Am Dent Assoc 2007; 138: 621-627.

8) Ayad NM. Susceptibility of restorative materials to staining by common beverages: an in vitro study. Eur J Esthet Dent 2007; 2: 236-247.

9) Mundim FM, Garcia Lda F, Pires-de-Souza Fde C. Effect of staining solutions and repolishing on color stability of direct composites. J Appl Oral Sci 2010; 18: 249-254.

10) Ardu S, Braut V, Gutemberg D, Krejci I, Dietschi D, Feilzer AJ. A long-term laboratory test on staining susceptibility of esthetic composite resin materials. Quintessence Int 2010; 


\section{1: 695-702.}

11) Ruyter IE, Nilner K, Moller B. Color stability of dental composite resin materials for crown and bridge veneers. Dent Mater 1987; 3: 246-251.

12) Mohamed-Tahir MA, Yap AU. Effects of $\mathrm{pH}$ on the surface texture of glass ionomer based/containing restorative materials. Oper Dent 2004; 29: 586-591.

13) Fukazawa M, Matsuya S, Yamane M. The mechanism for erosion of glass-ionomer cements in organic-acid buffer solutions. J Dent Res 1990; 69: 1175-1179.

14) Bagheri R, Burrow $M$, Tyas M. Influence of food simulating solutions and surface finish on susceptibility to staining of aesthetic restorative materials. J Dent 2005; 33: 389-398.

15) Engelhardt UH, Maier HG. Acids in coffee: The proportion of individual acids in the total titratable acid. Z Lebensm Unters Forsch 1985; 181: 20-23.

16) Micali B, Basting RT. Effectiveness of composite resin polymerization using light emitting diodes (LEDs) or halogen based light-curing units. Braz Oral Res 2004; 189: 266-270.

17) da Silva EM, Almeida GS, Poskus LT, Guimarães JG. Relationship between the degree of conversion, solubility and salivary sorption of a hybrid and a nanofilled resin composite.
J Appl Oral Sci 2008; 16: 161-166.

18) Samra AP, Perereira SK, Delgado LC, Borges CP. Color stability evaluation of aesthetic restorative materials. Braz Oral Res 2008; 22: 205-210.

19) Gonçalves F, Kawano Y, Pfeifer C, Stansbury JW, Braga RR. Influence of BisGMA, TEGDMA, and BisEMA contents on viscosity, conversion, and flexural strength of experimental resins and composites. Eur J Oral Sci 2009; 117: 442-446.

20) Gonçalves F, Azevedo CL, Ferracane JL, Braga RR. BisGMA/ TEGDMA ratio and filler content effects on shrinkage stress. Dent Mater 2011; 27: 520-526.

21) Emami N, Söderholm K. Young's Modulus and degree of conversion of different combination of light-cure dental resins. Open Dent J 2009; 1: 202-207.

22) Khokhar ZA, Razzoog M, Yaman P. Color stability of restorative resins. Quintessence Int 1991; 22: 733-737.

23) Domingos PA, Garcia PP, Oliveira AL, Palma-Dibb RG. Composite resin color stability: influence of light sources and immersion media. J Appl Oral Sci 2011; 19: 204-211.

24) Ertaş E, Güler AU, Yücel AC, Köprülü H, Güler E. Color stability of resin composites after immersion in different drinks. Dent Mater J 2006; 25: 371-376. 